efficacy intervention trial using novel supplementations Sprinkles (Suppleforte) was performed.

Methods Controlled cluster randomised trial. We compared the efficacy of Sprinkles (the Sprinkles arm received one-dose multiple micronutrients sachets) with the standard treatment (the Control arm received standard liquid iron and vitamins $A+D$ ) supplied free of charge to the families with children from 6 to $12 \mathrm{M}$ of age attending well-baby clinics. Infants were enrolled between July 2005 and September 2007 in 12 neighbourhood clinics (randomisation units, clusters).

Results The final study population comprised 621 eligible infants. There was a positive significant effect of intervention among children of Sprinkles groups on mean level of folic acid and zinc in both Bedouin and Jewish populations $(p<0.05)$. Sprinkles use was associated with a reduced risk of iron deficiency (at least 2 of 6 iron deficiency anaemia indicators) at age $12 \mathrm{M}$, compared with control intervention $(\mathrm{OR}=0.33, \mathrm{p}=0.001)$ after controlling for the $6 \mathrm{M}$ iron status, iron consumption from food, breastfeeding duration and reported supplementations use. More Control Bedouin children were hospitalised for any/all infectious disease cause $(27.2 \%)$, compared to the Sprinkles (14.6\%, $\mathrm{p}=0.005)$. Significantly more adverse events (changes in stool colour, diarrhoea, and constipation) were reported in Controls than in Sprinkles in both ethnic populations.

Conclusions Sprinkles supplementation was associated with a marked reduction in risk of iron deficiency at age $12 \mathrm{M}$ and less adverse events and should be recommended formulations.

\section{P2-374 BEHAVIOUR PROBLEMS AND OVERWEIGHT ADOLESCENTS: THE ROLE OF GENDER AND RESILIENCE}

doi:10.1136/jech.2011.142976l.5

N Boa-Sorte, D Santos, ${ }^{*}$ C Feitosa, L Santos. Institute of Collective Health, Federal University of Bahia, Salvador, Bahia, Brazil

It is well-recognised that obesity is a complex, multifactorial condition which includes both genetic and environmental factors. Although it is controversial, there is evidence that behavioural problems and being overweight are associated. Furthermore, relatively few studies have analysed the role of resilience in this relationship.

Objective To analyse the association between behaviour problems (BP) and the overweight condition (OW) among adolescents and to examine the role of resilience and gender.

Methods A cross-sectional study of 951 adolescents aged 11-18 years old who live in Monte Gordo district, a mixed ruralurban region in the northeast of Brazil. The overweight condition was defined as BMI/age z-score greater than +1SD (WHO, 2007). Behaviour problems were estimated by Youth Self Report (YSR/ $11-18)$. Resilience was measured by the Wagnild \& Young scale. The $90^{\text {th }}$ percentile was used as the cut-off for behavioural problems and resilience scores below the $25^{\text {th }}$ percentile was considered low resilience. OR was obtained using multiple logistic regression.

Results We observed an overweight prevalence of $14.7 \%$ and identified behaviour problems in $9.9 \%$ of subjects. The association between $\mathrm{BP}$ and the overweight condition remained after adjusting for gender, resilience, age, ethnicity and socio-economic level (OR: 2.06; $95 \%$ CI 1.23 to 3.46). Low resilience was not significant but following a stratified analysis for gender we observed an association between BP and OW only in females (OR: 2.54; 95\% CI 1.41 to 4.58$)$.

Conclusion The results demonstrate an association between behaviour disturbance and the overweight condition in female adolescents with no protective effect of resilience. We recommend greater incentives to reduce the stressors to which adolescents are exposed.

\section{P2-375 FAMILY HISTORY OF DIABETES: THE ROLE OF GRANDPARENTS DATA TO IDENTIFY ADOLESCENTS AT DIABETES RISK}

doi:10.1136/jech.2011.142976l.6

${ }^{1} \mathrm{M}$ Brandão, ${ }^{*}{ }^{1,2} \mathrm{C}$ Lopes, ${ }^{1,2} \mathrm{E}$ Ramos. ${ }^{1}$ Department of Hygiene and Epidemiology, Faculty of Medicine, University of Porto, Porto, Portugal; ${ }^{2}$ Institute of Public Health University of Porto (ISPUP), Porto, Portugal

Objective To evaluate the role of grandparents' history of diabetes on defining family history of diabetes in order to identify adolescents at high risk of diabetes.

Study design and Setting We evaluated 1276 population-based adolescents, aged 13-year-old, from Portugal. Data were collected by self-reported questionnaires and a clinical evaluation was performed, including a fasting blood sample.

Results The prevalence of impaired fasting glucose (IFG)/diabetes was $4.1 \%$ using American Diabetes Association (ADA) criteria and $0.94 \%$ using the WHO criteria. Using data only from Parental History, 103 adolescents (8\%) were identified has having a positive family history of diabetes, while combining both parental and grandparental history (Total Family History), 468 adolescents was additionally identified as having a positive history, performing a total of 571 adolescents (45\%). After adjusting for sex and parents education, the OR for having fasting plasma glucose $\geq 75$ th percentile considering only Parental History was 0.91 (95\% CI 0.57 to 1.47) and combining data from parents and grandparents the $\mathrm{OR}$ was 1.17 (95\% CI 0.83 to 1.65$)$. Parental History's sensitivity to identify IFG/diabetes by the ADA criteria was $2.6 \%$, while total family history's sensitivity (including grandparents' data) was $62 \%$. Conclusion Although there's no significant association between IFG and a positive family history, combining parental with grandparental history (total family history) lead to a 5.5-fold increase in the identification of adolescents with a positive family history. So, on adolescent screening, it seems better to use parental plus grandparental information instead of just relying on parental data.

\section{P2-376 DEVELOPING SUSTAINABLE EPIDEMIOLOGY CAPACITY AMONG PUBLIC HEALTH FIELD WORKERS IN ZAMBIA, RESULTS OF A PILOT TRAINING}

doi:10.1136/jech.2011.142976l.7

${ }^{1} \mathrm{~L}$ Burn, ${ }^{*} \mathrm{P}$ Amanzi, ${ }^{3} \mathrm{~K}$ Chilemu, ${ }^{4} \mathrm{D}$ Daka, ${ }^{5} \mathrm{~V}$ Chisumpa, ${ }^{5} \mathrm{~A}$ Banda, ${ }^{6} \mathrm{~J}$ Nikisi, ${ }^{7} \mathrm{G}$ Meredith, ${ }^{7} \mathrm{~W}$ Craytor, ${ }^{7} \mathrm{E}$ Martin, ${ }^{7} \mathrm{E}$ Mwenda, ${ }^{8} \mathrm{M}$ Mumba, ${ }^{1} \mathrm{R}$ Keating, ${ }^{1} \mathrm{I}$ Membe, ${ }^{1} \mathrm{~L}$ M Mwapela, ${ }^{1} \mathrm{~S}$ Kamocha, ${ }^{1} \mathrm{M}$ Marx, ${ }^{9} \mathrm{EDU}$ Steering Committee. ${ }^{1}$ Global AIDS Program, Centers for Disease Control and Prevention, Lusaka, Zambia; ${ }^{2}$ Ministry of Health, Lusaka, Zambia; ${ }^{3}$ National HIVIAIDS/STI/TB Council, Lusaka, Zambia; ${ }^{4}$ Central Statistics Office, Lusaka, Zambia; ${ }^{5}$ University of Zambia, Lusaka, Zambia; ${ }^{6} \mathrm{Jhpiego,} \mathrm{an}$ affiliate with Johns Hopkins University, Lusaka, Zambia; ${ }^{7}$ National Alliance of State and Territorial AIDS Directors, Lusaka, Zambia; ${ }^{8}$ Center for Infectious Disease Research in Zambia, Lusaka, Zambia; ${ }^{9}$ Epidemiology for Data Users, Lusaka, Zambia

Introduction District and provincial-level public health field workers in Zambia collect, compile, and send data from various sources to national counterparts. However, these workers have had limited data training. They need skills to generate relevant, quality data, analyse them, and use them for local decision-making. A steering committee, comprised of the Zambian Ministry of Health, University of Zambia, National AIDS Council, Central Statistics Office, United States Centers for Disease Control and Prevention, and others, developed a training program for these workers to obtain these skills and build sustainable epidemiology capacity in Zambia. Methods We developed curricula to teach standardised data collection, summarisation, interpretation and use. The training was piloted among 12 district and provincial-level staff in December 2010. The pre-post test and course evaluations were linked directly 